\title{
O KaliapParat
}

\author{
Raquel Gonçalves-Maia* \\ Departamento de Química e Bioquímica, Faculdade de Ciências da Universidade de Lisboa \\ rmcgonc@gmail.com
}

\begin{abstract}
The Kaliapparat - The Kaliapparat is a small instrument that belongs to the History of Chemistry. Small, yes, now forgotten, and yet so fundamental for a period of several decades in the nineteenth century in organic analysis with the purpose to establish correct empirical formulas of compounds. The great German chemist Justus von Liebig was the author and the technical innovation he introduced is unquestionable.

Pictures of Liebig, laboratory drawings of the Giessen School designed by Wilhelm von Trautschold, the American Chemical Society and the Sterling Chemistry Laboratory honor us with its presence.

At Porto, Portugal, the Medical Laboratory Prof. Alberto de Aguiar, most likely the first private clinical analysis laboratory of the Iberian Peninsula also paid the deserved tribute to the Kaliapparat.
\end{abstract}

$\mathrm{O}$

Kaliapparat é um pequeno instrumento que faz parte da História da Química. Pequeno, sim, hoje esquecido, e, no entanto, tão fundamental durante um período de várias décadas no século XIX, na análise orgânica com vista ao correto estabelecimento das fórmulas empíricas dos compostos. O grande químico alemão Justus von Liebig foi o seu autor e a inovação técnica por ele introduzida é inquestionável.

Retratos de Liebig, desenhos do laboratório da Escola de Giessen, da autoria de Wilhelm von Trautschold, a American Chemical Society e o Sterling Chemistry Laboratory honram-no com a sua presença.

Em Portugal, o Laboratório Médico Prof. Alberto de Aguiar, muito provavelmente o primeiro laboratório de análises clínicas particular da Península Ibérica, sediado no Porto, também prestou a merecida homenagem ao Kaliapparat.

\section{Análise elementar}

Desde os tempos de Antoine Laurent de Lavoisier (1743-1794) que a análise quantitativa de compostos orgânicos, a análise por combustão, foi considerada indispensável para a sua caracterização. Para cada novo composto seria necessário conhecer a quantidade de carbono, hidrogénio, oxigénio e, eventualmente, de nitrogénio, que o compunham, de forma a estabelecer a sua fórmula empírica [1].

A combustão de uma amostra, de pelo menos 50 g, conduzia à formação de vapor de água e de dióxido de carbono; o primeiro condensava e era coletado num frasco e o segundo era absorvido por uma solução de hidróxido de potássio, sob agitação. A medição do aumento de peso de ambas as partes do sistema permitia a determinação da quantidade de hidrogénio e de carbono, respetivamente. Como se depreende, tratava-se de uma análise "em grande escala" e sujeita a grande erro. Para mais, obrigava à existência de vários operadores simultaneamente, um para introduzir o ar, outro a amostra, um terceiro para acender o pavio de combustão, um quarto para agitar a solução recetora do dióxido de carbono, ... Um verdadeiro “quebra-cabeças”.

O britânico William Prout (1785-1850) bem tentou "simplificar” o sistema e torná-lo mais preciso [2,3]. Para isso, misturava a amostra a ser analisada com óxido de cobre $(\mathrm{CuO})$ num tubo de vidro colocado na horizontal entre dois

* Professora Catedrática aposentada.

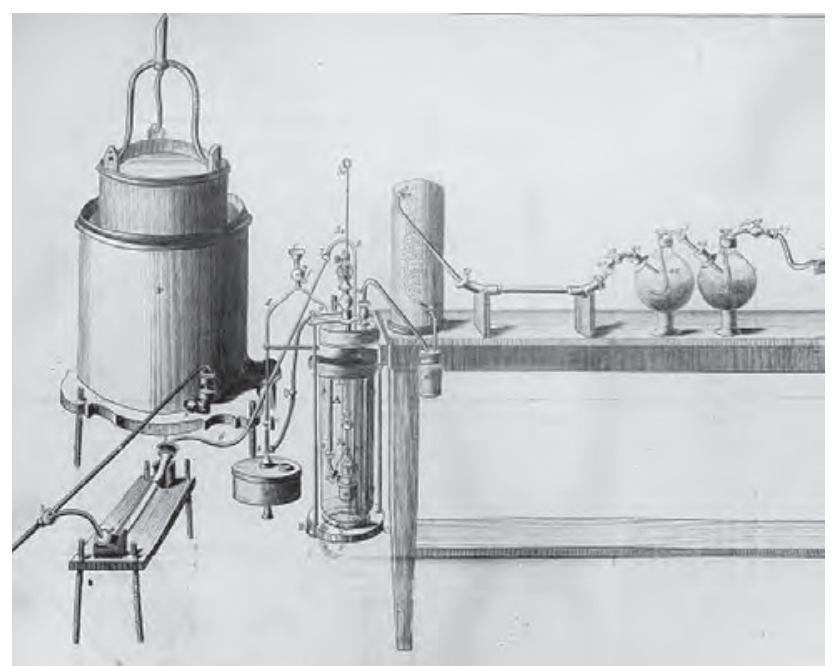

Figura 1 - Dispositivo de análise orgânica elementar (1789) - Traité élémentaire de chimie de Antoine Laurent de Lavoisier; desenho de Marie-Anne Paulze Lavoisier [1]

tubos em U contendo oxigénio sobre mercúrio. A chama múltipla de uma lamparina de álcool provocava a oxidação da amostra pelo óxido. O produto formado, $\mathrm{Cu}_{2} \mathrm{O}$, era então reoxidado a $\mathrm{CuO}$ com oxigénio passado várias vezes para frente e para trás sobre a amostra, por escoamento do mercúrio nos tubos em U. Arrefecida a mistura, media-se a diferença gasosa volumetricamente o que, segundo Prout, permitia conhecer a razão hidrogénio/oxigénio no composto orgânico. Numa experiência adicional, sem oxigénio, o aumento de volume de $\mathrm{CO}_{2}$ indicava a quantidade de carbono na amostra. Embora as amostras em estudo pudessem ser de muito menor dimensão ( $\sim 0,5$ g) do que as utilizadas 
pela técnica proposta por Lavoisier, seria impossível obter, por medições de volume, dados precisos.

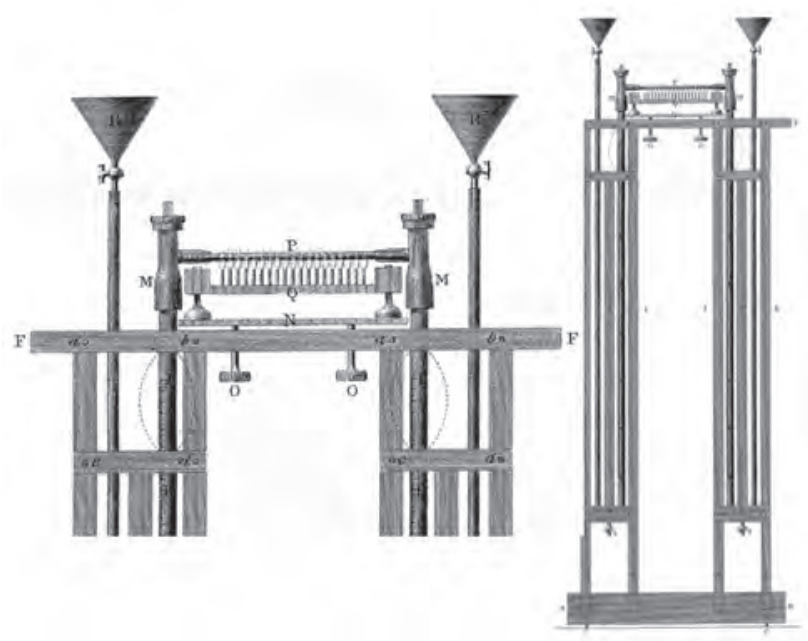

Figura 2 - Dispositivo de análise elementar de William Prout [2]

A tal "simplificação”, como bem se depreende, redundou numa considerável complicação; e a precisão obtida não era superior. O aparelho de Prout foi altamente criticado pelos seus contemporâneos.

A determinação de nitrogénio numa amostra era um problema ainda mais difícil de resolver, uma vez que era praticamente impossível excluir traços deste elemento atmosférico e coletar o nitrogénio puro, sem misturas de óxidos, proveniente da combustão.

No contexto dos primórdios da análise orgânica elementar, dois cientistas sobressaem pela qualidade das suas intervenções: o sueco Jöns Jacob Berzelius (1779-1848), em Estocolmo, e o francês Louis Joseph Gay-Lussac (1778-1850), em Paris [4-6]. Foram dois marcos na análise orgânica elementar. Mas, não se depreenda que isso correspondesse a um metodologia muito mais eficaz ou a uma técnica superior. Facto é que, ao longo dos anos 1820, Berzelius e Gay-Lussac foram os únicos que, sistematicamente, publicaram resultados sobre a natureza de moléculas orgânicas que pouco se afastam dos resultados que as tecnologias atuais nos oferecem (difração de raios-X, espetroscopia estrutural ou mecânica quântica química, por exemplo). Nos seus artigos, porém, não se especifica a combustão das amostras em pormenor, referindo-se apenas como sendo "o método usual” ou “o procedimento habitual”, isto é, assumindo que os leitores já com ela estavam familiarizados. Era a extraordinária perícia dos dois investigadores, aliada a uma intuição e prática intensas, que permitiam a elevada qualidade das análises obtidas. No entanto, certas particularidades denotam o enorme cuidado com que tudo era executado, desde a purificação dos compostos em estudo, à perfeita secagem das amostras antes da combustão, à combustão em vácuo para eliminar o nitrogénio atmosférico e à forma expedita de coletar e medir os gases libertados.

A análise elementar de compostos orgânicos era um verdadeiro desafio. Por um lado, a utilização de pequenas amostras na combustão podia conduzir a resultados com erro significativo; por outro, o uso de amostras de grande porte provocava a libertação de uma quantidade de gás de difícil controle. Se o composto em estudo tinha pequena massa molecular, o problema estava razoavelmente solucionado. Todavia, se a massa molecular fosse elevada, como é comum em tantos compostos orgânicos, e para mais se voláteis, as limitações da técnica podiam ser muito importantes e a análise elementar subsequente muito imprecisa.

Em resumo, pode afirmar-se que, salvo raras exceções, atingiu-se os anos 30 do século XIX sem que fosse possível generalizar uma análise orgânica elementar que conduzisse a resultados de indiscutível precisão.

\section{LIEBIG E O APARELHO DAS CINCO ESFERAS}

Justus von Liebig (1803-1873) nasceu em Darmstadt, na Alemanha [5-8]. Terá iniciado o seu interesse pela Química no pequeno laboratório onde o pai, comerciante de produtos de drogaria e de materiais de pintura, preparava alguns dos seus produtos de venda. Após frequentar com êxito as Universidades de Bona e de Erlanger, tinha então 20 anos, rumou a Paris, ao encontro da Química de melhor qualidade a nível mundial; para isso, dispunha de uma bolsa por seis meses, que ele se encarregou de transformar em dezassete. Trabalha, então, com Louis Jacques Thénard (1777-1857) primeiro e, depois, com Gay-Lussac.

De regresso à Alemanha, entra na Universidade de Giessen e, logo no ano seguinte, é promovido a "full professor”. Segue-se a criação de um laboratório de investigação, privado, a Escola (Laboratório) de Giessen [9], com ênfase nos procedimentos da análise química orgânica. Ao contrário dos primeiros laboratórios existentes, dirigidos à preparação de fármacos e ao auxílio medicinal, a grande novidade desta escola vai residir no ensino da investigação em Química. Era um local de trabalho pouco estruturado, mas com um ambiente aprazível, informal e, indubitavelmente, criativo. Trabalhava-se muito e muitas horas. Abria as portas pelas seis da manhã e só as fechava pelas vinte e duas e trinta; com dois intervalos diários e descanso ao domingo. Todo o material de vidro utilizado na escola de Liebig era produzido pelos próprios investigadores que a integravam, com o apoio do instrutor laboratorial Karl (ou Carl) Jacob Ettling (1806-1856); Ettling doutorou-se em 1846.

Em 19 de dezembro de 1830, Friedrich Wöhler (1800-1882), o químico alemão com quem Liebig mantinha uma sólida amizade, escreve ao seu mentor Berzelius. Na carta, pode ler-se a seguinte passagem: Estou ansioso por apreender o novo método de análise orgânica [de Liebig] $[5,10]$. Novo método? A que se refere Wöhler?

Pouco tempo passado, é o próprio Liebig quem elucida Berzelius, em carta datada de 8 de janeiro de 1831. Adicionemos a sua descrição, logo publicada na revista científica Annalen der Physik [11], e de pronto arquitetaremos... o Kaliapparat. 


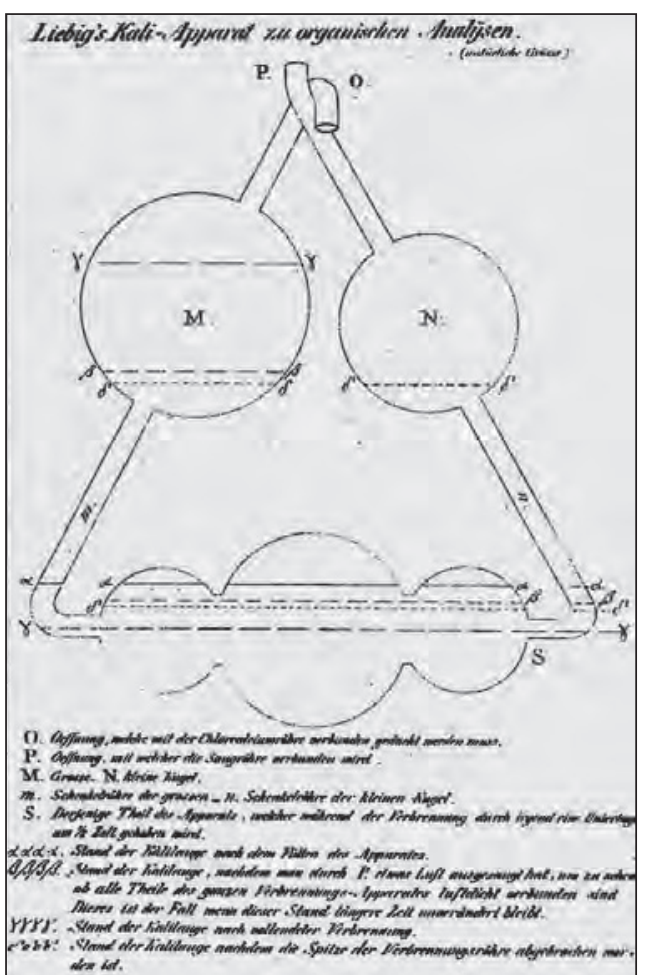

$2 \rightarrow \infty$.

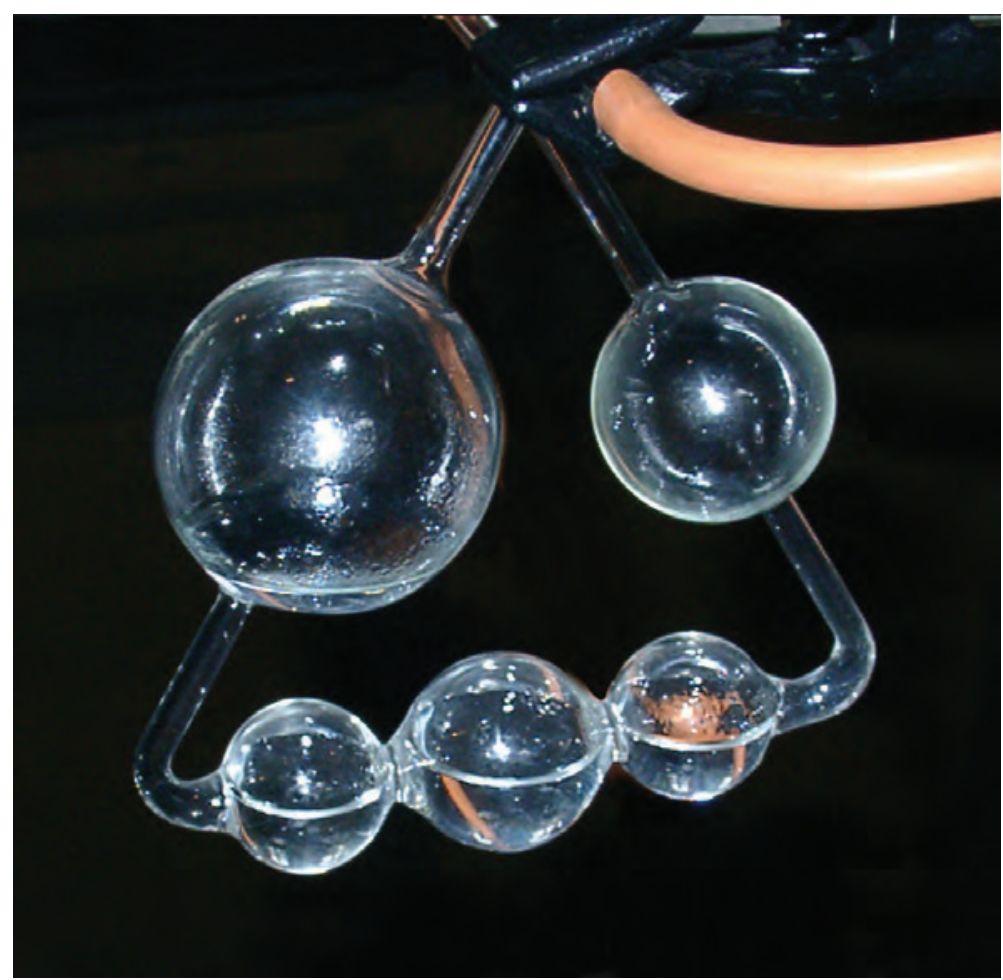

Figura 3 - O Kaliapparat
O pequeno e delicado aparelho que dá pelo nome de $\mathrm{Ka}$ liapparat [12-15], da autoria de Liebig em parceria com Ettling, é uma peça tubular em vidro, de aspeto triangular, composta por cinco bolas, ou bolbos, em sucessão. Três das bolas dispõem-se segundo um eixo em posição horizontal, a base do triângulo, enquanto que as outras duas se encontram, uma de cada lado, num plano superior. Uma solução de hidróxido de potássio capturava o dióxido de carbono proveniente da combustão da amostra, o qual era fixado sob a forma de carbonato de potássio. As bolas superiores preveniam o transbordo da solução borbulhante no decurso da combustão. O aparelho era cuidadosamente pesado - Liebig dispunha de uma balança analítica de grande precisão [16] - antes e depois da total combustão. A queima de uma amostra que produzisse $1 \mathrm{~g}$ de dióxido de carbono podia ser pesada com um erro inferior a $0,1 \%$. O vapor de água, por seu turno, era absorvido num tubo contendo cloreto de cálcio, higroscópico, e a alteração do peso cuidadosamente registada.

Acresce que a determinação gravimétrica rigorosa do carbono existente numa amostra servia ainda de controle no que respeita à exatidão dos resultados da determinação, volumétrica, do nitrogénio.

O aumento de precisão dos resultados das análises elementares subiu em flecha; e a simplificação do manuseamento da aparelhagem também. Liebig não se cansou de demonstrar a superioridade do seu método, o que facilmente evidenciou através da elevada qualidade das análises assim efetuadas.

Em 1832, Berzelius mostrou-se encantado com a utilização do "seu” Kaliapparat, expedido por Liebig nove meses antes; dois tinham seguido viagem, um chegara intacto.
Jean-Baptiste Dumas, o famoso químico e político francês, abraçou a descoberta, após introduzir-lhe alguns refinamentos [3,17].

Durante várias décadas, o Kaliapparat e a balança de precisão foram os instrumentos fundamentais no laboratório de Química. A sua utilização começou a dissipar-se nos primórdios do século XX quando os métodos microanalíticos entraram em ação; envolviam amostra de muito menor porte, balanças de muito maior precisão e a fixação do carbono em fase sólida ao invés de em solução.

\section{A notoriedade do Kaliapparat}

O Kaliapparat de Liebig foi peça fundamental na análise elementar de compostos orgânicos durante três quartos de século. Tornou-se um símbolo da Química Orgânica. O tempo e os avanços tecnológicos, em conjunção, relegaram-no para o esquecimento. Marcos significativos, porém, permitem refrescar a nossa memória que deve ser preservada.

Justus von Liebig teve plena consciência da importância da sua descoberta. Foi um dos cientistas mais retratados ao longo da vida e, como não podia deixar de ser, num dos seus retratos, datado de 1852, surge, sentado, exibindo um pequeno caderno onde simula escrever os resultados extraídos do seu aparelho, em posição de destaque [18]. Num esboço de perfil, de corpo inteiro, Liebig inclina a cabeça por sobre a bancada do seu laboratório onde o Kaliapparat desempenha a sua função.

Em 1840, o laboratório de análise da Escola de Giessen, em plena atividade de pesquisa, foi desenhado por Wilhelm von Trautschold; foram treze os investigadores re- 

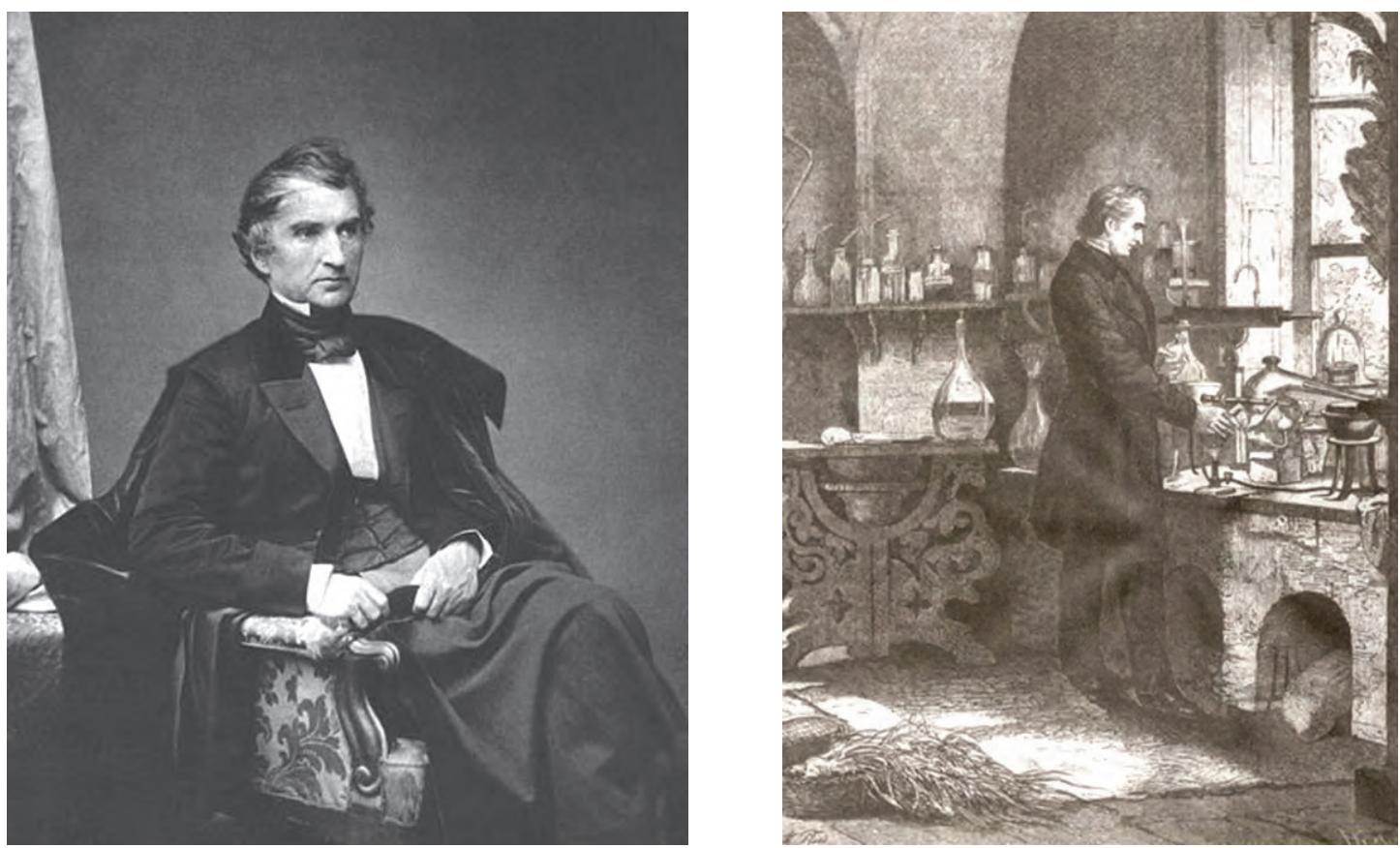

Figura 4 - Retrato (autor: Franz Hanfstaengl) e gravura de Justus von Liebig frente ao Kaliapparat

presentados. O primeiro esboço foi feito a preto e branco e a versão final a cores. À esquerda, o mexicano Vicente Ortigosa (1817-1877) sustém o Kaliapparat na sua mão direita (voltado para cima na versão inicial e, para baixo, na versão final) [19].
Iorque na University of the City of New York (depois de 1896, New York University). A seu ver, os avanços da Química justificavam a instituição de uma sociedade própria, à margem da American Association for the Advancement of Science. Tinham razão. Foi um dos seus fundadores, John

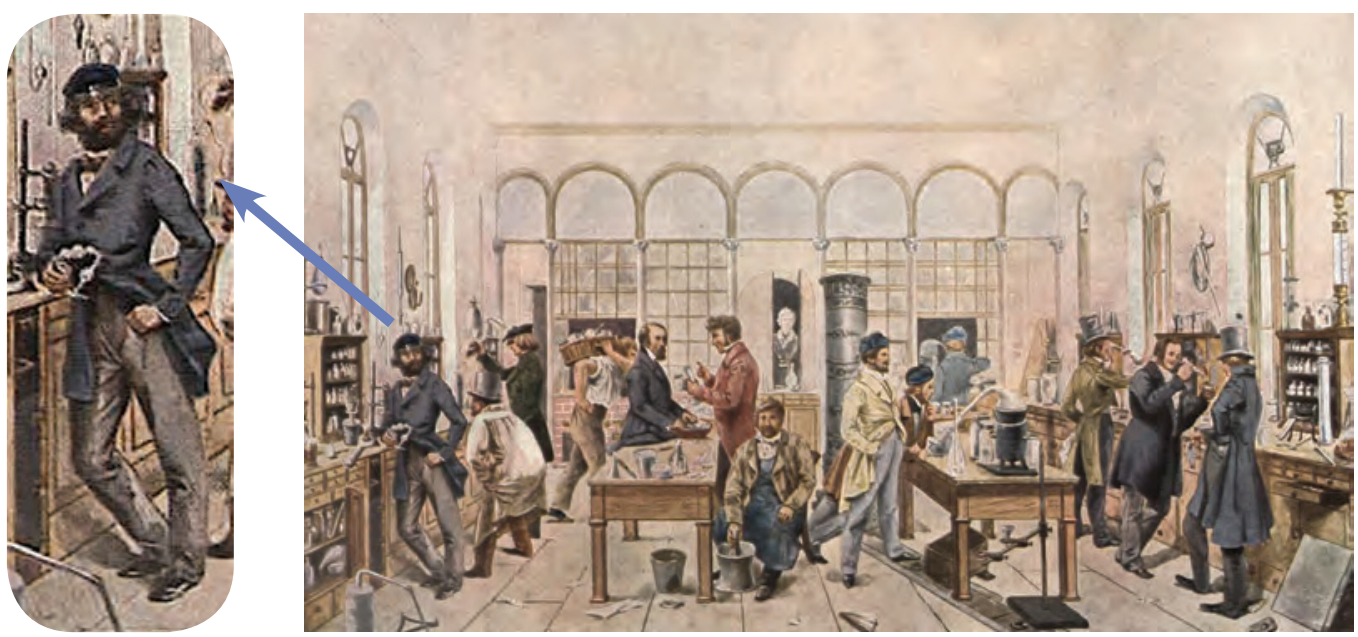

Figura 5 - Laboratório de Análise da Escola de Gissen; desenho de Wilhelm Trautschold (1815-1877)

Liebig não se fez representar entre os seus discípulos, mas terá, porventura, permitido ser Ortigosa o detentor do elegante aparelho de vidro. Das mãos de Ortigosa, dizia-se, saíam as melhores análises elementares, que, por vezes, corrigia o mestre...

Muito significativo da importância que o Kaliapparat chegou a deter é o facto de ter sido adotado como parte fundamental no logotipo da American Chemical Society [20].

A American Chemical Society (ACS), uma das mais reputadas sociedades científicas de Química em todo o mundo, foi fundada em 6 de Abril de 1876, durante uma reunião de 35 químicos do College of Pharmacy da Cidade de Nova
Lawrence Smith (1818-1883), antigo discípulo de Liebig em 1842, quem propôs a introdução de um estilizado $\mathrm{Ka}$ liapparat no logotipo da nova sociedade.

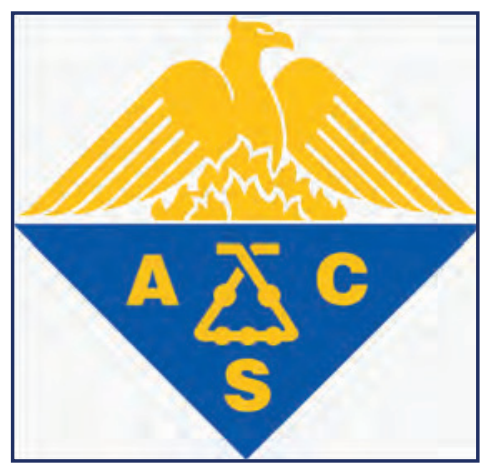

Figura 6 - Logotipo da American Chemical Society 
Na Rússia Imperial foi publicado, entre 1890 e 1907, o dicionário enciclopédico Brockhaus and Efron em 35 volumes, na sua versão de grande formato (e 86 volumes, na de pequeno formato). No equipamento de laboratório, entre cadinhos, almofarizes e pinças, um Kaliapparat, algo reformulado, marca a sua presença.

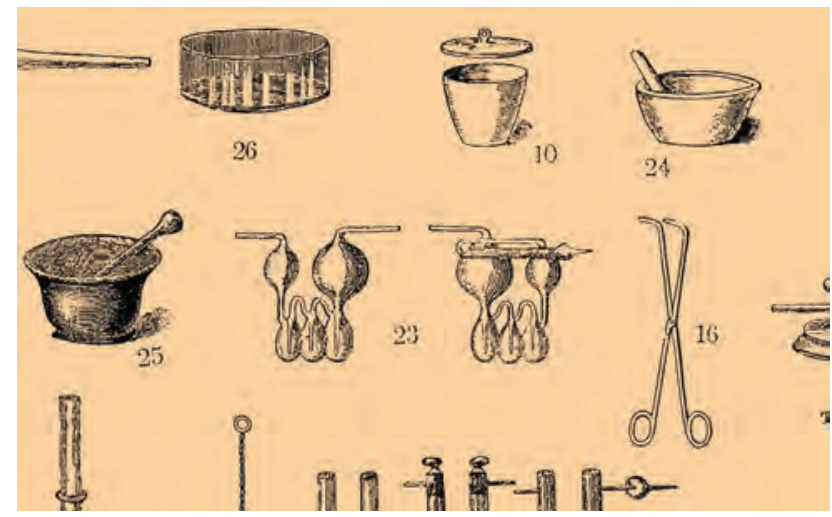

Figura 7 - Pormenor de uma ilustração do Dicionário Enciclopédico Brockhaus \& Efron (1890-1907)

Na Universidade de Yale (New Haven, Connecticut), uma das mais antigas e mais reputadas universidades dos EUA, fundada em 1701, no Sterling Chemistry Laboratory (SCL) construído em 1923 segundo projeto do arquiteto William Adams Delano, o Kaliapparat ocupa lugar de destaque [21]. Edifício de três andares, atualmente em renovação, tem instruído, ao longo dos anos, inúmeros estudantes de Química e de ciências afins. No exterior do imóvel, de estilo gótico, são várias as placas alusivas à História da Química. De entre elas destaca-se aquela onde tão bem se visualiza o Kaliapparat [3].

A Biblioteca de Química do Sterling Chemistry Laboratory também nos brinda com um escudo em cuja madeira gravada sobressai o Kaliapparat.

Em 2003 comemorou-se a passagem de duzentos anos sobre o nascimento de Justus von Liebig. Na ocasião, foram muitas as manifestações de apreço pela obra do ilustre químico. O correio alemão editou um selo comemorativo onde, a par com o busto do cientista, surge inevitavelmente o Kaliapparat.

\section{O Kaliapparat no Laboratório Médico Prof. Alber- TO DE AGUIAR}

O Laboratório Médico Prof. Alberto de Aguiar é uma verdadeira joia do património cultural português, quer científico, quer artístico. Uma peça rara de inestimável valor. Fundado no Porto em 1897 pelo Professor Alberto Pereira Pinto de Aguiar foi, muito provavelmente, o primeiro laboratório de análises clínicas particular da Península Ibérica; mudou-se para a Rua da Restauração em 1904. Aqui teve as suas portas abertas desde aquela data até 2009, tendo sofrido várias ampliações nas primeiras décadas do seu funcionamento. Ocupava cerca de $400 \mathrm{~m}^{2}$, divididos por 14 secções de serviços [22,23]. O laboratório era especializado em análises clínicas (urologia, bacteriologia, serologia,
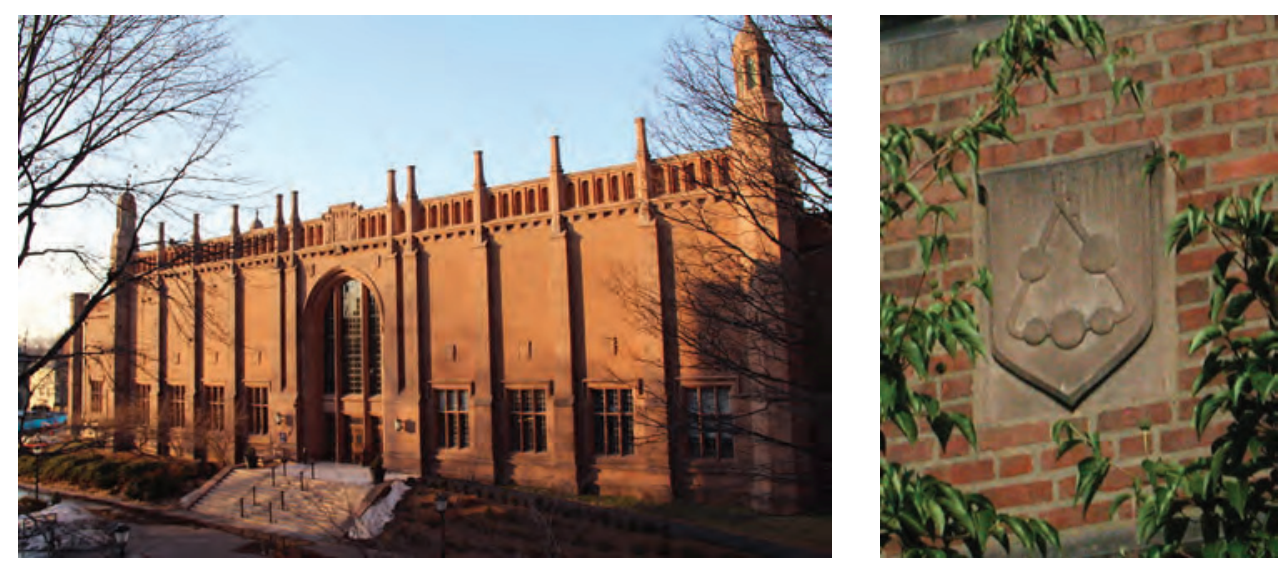

Figura 8 - Fachada do Sterling Chemistry Laboratory, fotografia de Nick Allen; placa alusiva ao Kaliapparat [3]

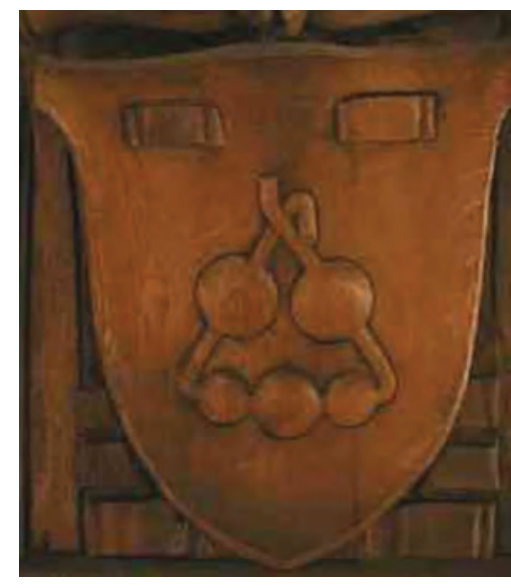

Figura 9 - Escudo em talha com o Kaliapparat Biblioteca de Química do Sterling Chemistry Laboratory [3]

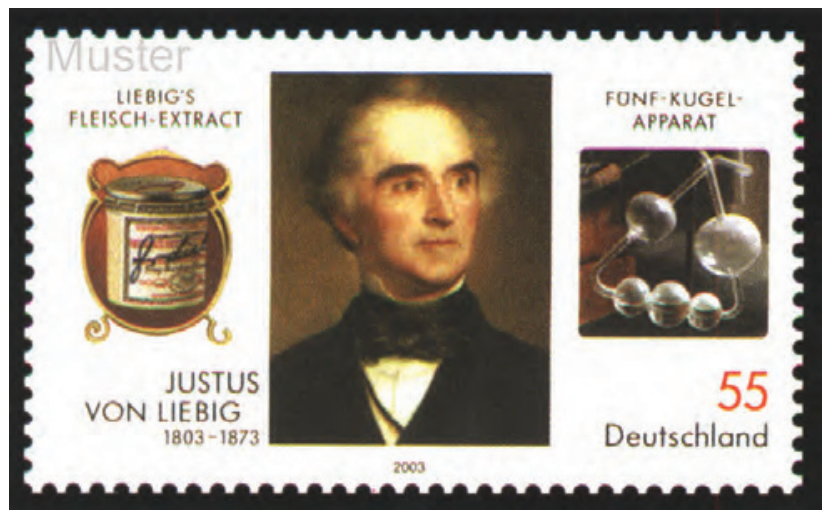

Figura 10 - Selo comemorativo do bicentenário do nascimento de Liebig 
hematologia, etc.), embora também realizasse exames de outra natureza (higiénicos, toxicológicos, hidrominerais, etc.), numa combinação perfeita entre clínica e laboratório.

Alberto de Aguiar era um homem de ciência invulgar. Ao seu estudo e prática químico-médica, associava um grande conhecimento de Arte. O Laboratório Médico é, em si mesmo, o exemplo desta inter-relação. Painéis de azulejos e frisos decorativos percorrem as diferentes salas e extasiam o nosso olhar. É grande o seu valor artístico e quase solene o encantamento que nos transmite.

Referimos, em particular, os medalhões que representam os mestres da Medicina portuense, da autoria do pintor cerâmico Pedro Figueiredo [24], e o friso onde vasos de combustão, retortas, cápsulas, cadinhos... e o Kaliapparat, criação muito provável do professor de desenho Van Krieck, estão presentes. Difícil encontrar lugar mais primoroso para homenagear tão delicada peça, herança magnífica da História da Química.
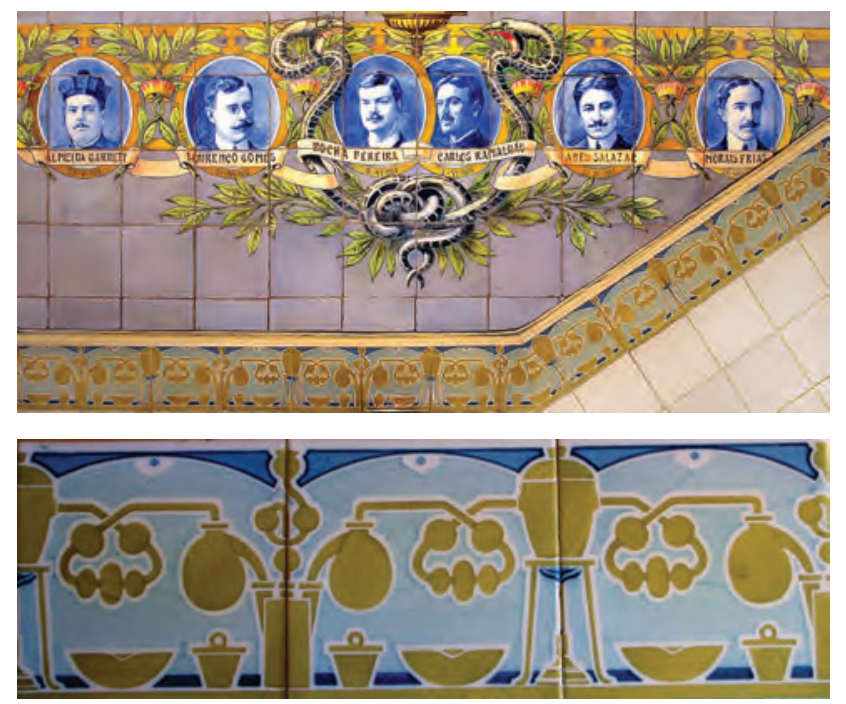

Figura 11 - Painel decorativo em azulejo do Laboratório Médico Prof. Alberto de Aguiar, fotografia de Ângelo Sande; pormenor do friso

Os descendentes, e atuais proprietários, do Laboratório Médico Prof. Alberto de Aguiar procuram assegurar que alguma instituição/fundação nacional assuma e preserve o inestimável património histórico que o Laboratório proclama.

A importância deste valioso monumento nacional, e mesmo internacional, bem justifica que a ele regressemos num próximo artigo.

\section{AgradeCIMENTO}

A José Pedro Aguiar Côrte-Real, neto do Prof. Alberto de Aguiar e filho dos Drs. Eugénio Côrte-Real e Alda Aguiar, muito agradeço a disponibilidade do acesso ao edifício “Laboratório Médico Prof. Alberto de Aguiar”, as preciosas informações prestadas e a oferta de publicação das correspondentes fotografias que ilustram este artigo.

\section{REFERÊNCIAS}

[1] A.L. Lavoisier, Traité élémentaire de chimie, vol. II, Cap. VII, Librairie Cuchet, Paris 1789.

[2] W. Prout, Phil. Trans. R. Soc. Lond. 117 (1827) 355-388. http://rstl.royalsocietypublishing.org/content/117/355.full. pdf+html (acedido em 16-05-2015)

[3] Combustion Analysis, Liebiganal https://webspace.yale. edu/chem125/125/history99/4RadicalsTypes/Analysis/ Liebiganal.html (acedido em 16-05-2015)

[4] A.J. Ihde, The Development of Modern Chemistry, Dover Publications, Nova Iorque, 2012.

[5] A.J. Rocke, Nationalizing Science: Adolphe Wurtz and the Battle for French Chemistry, MIT Press, Cambridge, Massachusetts, 2001.

[6] A.J. Rocke, em Instruments and Experimentation in the History of Chemistry, cap. 11, ed. F.L. Holmes e T.H. Levere, MIT Press, Cambridge, Massachusetts, 2000.

[6] R. Gonçalves-Maia, O Legado de Prometeu - Uma Viagem na História das Ciências, Escolar Editora, Lisboa, 2006.

[7] W.J. Brock, Justus von Liebig: The Chemical Gatekeeper, Cambridge University Press, Cambridge (RU), 2002.

[8] J.H. Maar, Quim. Nova 29 (2006) 1129-1137.

[9] A Escola-Laboratório de Giessen foi transformada em museu científico, o Museu Liebig. Fundado em 1920, conserva em excelente estado salas e instrumentos de trabalho da época (1824-1852) em que Justus von LIebig aí viveu e investigou. É considerado Local Histórico da Química. http:// www.liebig-museum.de/ (acedido em 16-05-2015)

[10] Briefwechsel zwischen J. Berzelius und F. Wöhler, ed. O. Wallach, Engelmann, Leipzig, 1901. https://archive.org/details/briefwechselzwis02berzuoft (acedido em 16-05-2015)

[11] J. Liebig, Annalen der Physik [2] 21 (1831) 1-43.http://babel.hathitrust.org/cgi/pt?id=mdp.39015065410733;view=1 up;seq=10 (acedido em 16-05-2015)

[12] Fünf-Kugel-Apparat, no original alemão. Não se conhece a sua designação em português. É algumas vezes mencionado como o aparelho das "cinco esferas" ou dos "cinco bolbos".

[13] Kali provém da palavra árabe qalay, que significa calcinar; al-qalay refere-se à substância que é calcinada. Al-kali era o resíduo (cinzas) que certas plantas originavam quando eram queimadas, após ser passado por água seguida da sua evaporação. Em geral constituído por carbonatos de metais alcalinos, deram o símbolo K ao potássio (Kalium; Berzelius).

[14] J. Liebig, Anleitung zur Analyse organischer Körper, Verlag Vieweg, Braunschweig, 1837. https://archive.org/details/anleitungzuranal00lieb (acedido em 16-05-2015)

[15] A.J. Rocke, em Instruments and Experimentation in the History of Chemistry, cap. 11, ed. F.L. Holmes e T.H. Levere, MIT Press, Cambridge, Massachusetts, 2000.

[16] A balança analítica de Justus von Liebig, feita por um artífice local de nome Hess, conseguia pesar $100 \mathrm{~g}$ com a precisão de 0,3 mg, um grande feito para a época. 
[17] J. Dumas, J.S. Stafs, Justus Liebig Annalen der Chemie 38 (1841) 141-195.

[18] The Edgar Fahs Smith Memorial Collection, direitos de reprodução do Deutsches Museum, Alemanha. http://sceti. library.upenn.edu/sceti/smith/Apparatus.cfm?PictureID=2 69\&ApparatusID=104\&MaterialID $=\&$ FunctionID $=\&$ Era ID = (acedido em 16-05-2015)

[19] Depois da sua estada em Giessen, Ortigosa regressou ao país de origem, onde durante algum tempo exerceu o cargo de consultor científico junto do Imperador. A instabilidade governativa ditou a sua curta duração; dedicou-se ao comércio [8].

[20] ACS - Chemistry for Life, The First 100 Years. http://www.acs. org/content/acs/en/about/history.html (acedido em 16-05-2015)

[21] O Sterling Chemistry Laboratory foi o primeiro edifício da Universidade de Yale a ser construído por doação do benfeitor John William Sterling, advogado apaixonado por História, antigo aluno de Yale.

[22] A. de Aguiar, O “Laboratório Médico" do Prof. Alberto de Aguiar, tip. Mendonça, Porto, 1922.

[23] F.C. Pacheco, Um Século de Medicina Laboratorial. O Laboratório Médico Prof. Alberto de Aguiar, Ordem dos Médicos - Conselho Regional do Norte, Porto, 1998.

[24] O pintor Pedro de Figueiredo (Ferreira) (1880-1972) era natural de Tondela, mas exerceu quase toda a sua atividade no Porto, onde foi professor da Escola Industrial Faria Guimarães, hoje Escola Secundária Artística de Soares dos Reis. Foi discípulo de Jorge Colaço, o grande mestre dos admiráveis painéis que converteram a Estação Ferroviária de Porto-São Bento numa das mais belas estações do Mundo.

\section{Actualidades Científicas}

\section{SENSORES PARA DETECÇÃO DA DETERIORAÇÃO DE ALIMENTOS}

Há muitos anos foi sugerido o uso de sensores químicos baratos para detecção de compostos libertados no processo da deterioração de alimentos e, assim, monitorizar de forma mais eficaz a sua frescura para consumo humano. Recentemente, um grupo de investigadores nos EUA deu um passo na direcção desse objectivo através do estudo de nanotubos de carbono contendo complexos de cobalto-porfirina.

As datas de validade dos alimentos garantem-nos a devida segurança para o seu consumo mas, quando se seguem à risca, geram muito desperdício pois frequentemente são descartados muitos alimentos em perfeito estado de conservação. Estes desperdícios poderiam ser significativamente reduzidos caso fosse possível monitorizar em tempo real o estado de conservação dos alimentos através do controlo dos gases libertados durante o processo da sua deterioração, em particular as aminas biogénicas, tais como a putrescina e cadaverina. Com esta ideia em mente, Timothy Swager e o seu grupo no MIT em Boston, EUA, estudaram um conjunto de potenciais sensores para aminas baseados em nanotubos de carbono funcionalizados com vários complexos de cobalto contendo ligandos porfirina.

Os sensores estudados mostraram um limite de detecção inferior a 0,5 ppm para o amoníaco e excelentes respostas para a putrescina e cadaverina. Fizeram, então, medições dos gases azotados libertados em amostras de bacalhau, salmão, frango e carne de porco durante quatro dias e os resultados obtidos revelaram boa correspondência com a deterioração esperada para estes alimentos.

Timothy Swager referiu que o desafio central em sensores químicos é a selectividade e que o seu grupo criou sistemas que são altamente selectivos para aminas através de uma abordagem mais química em contraponto a outros investigadores na área, que têm tido uma abordagem mais orientada para a implementação de instrumentos/dispositivos. O passo seguinte será implementar a inclusão destes sensores em embalagens de alimentos para que possam fornecer dados em tempo real.

(adaptado de "Carbon nanotube-based sensor detects meat spoilage”, http://www.rsc.org/chemistryworld/2015/04/ carbon-nanotube-sensor-detects-meat-spoilage e S.F. Liu, A.R. Petty, G.T. Sazama, T.M. Swager, Angew. Chem. Int. Ed., 2015 - DOI: 10.1002/anie.201501434)

Paulo Mendes (pjgm@uevora.pt)

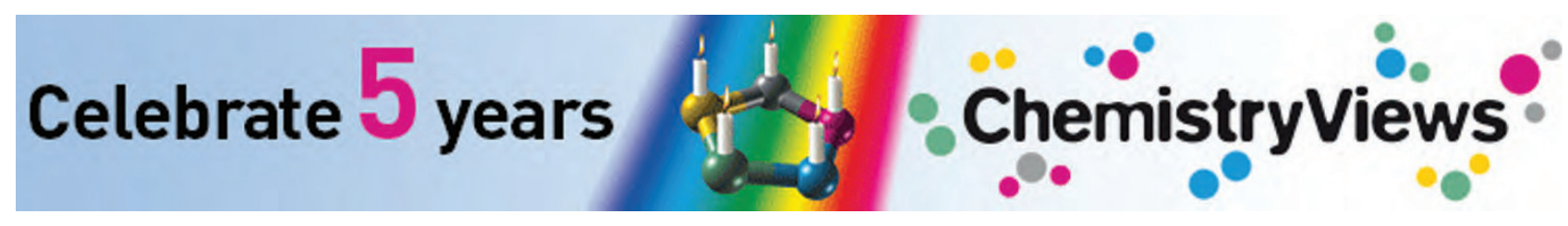




\section{Made in Europe}

for the World

2011. Volume 4. 12 Issues

ISSN print 1864-5631

ISSN electronic 1864-564X

ChemSusChem

brings together the latest developments in chemistry, energy and materials research for a more sustainable future

- publishes Communications, Full Papers, Reviews, Highlights, Book Reviews and more

is published monthly

is a sister of Angewandte Chemie

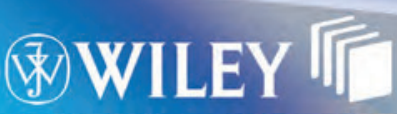

ONLINE LIBRARY

\section{CHEMSUSCHEM \\ (}

Impact Factor*

4.767

*2009 Journal Citation Report

(Thomson Reuters, 2010)

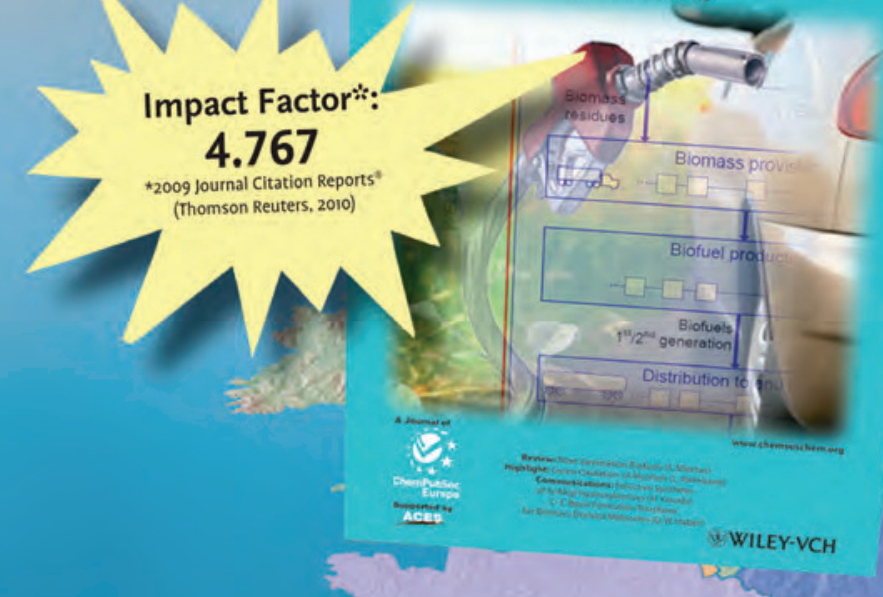

\section{(1)}
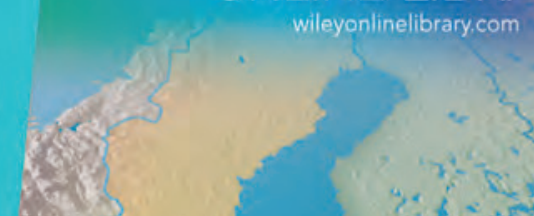